\title{
7. Public budgets and budgeting in Europe: state of the art and future challenges
}

Iris Saliterer, Mariafrancesca Sicilia, Ileana Steccolini

\begin{abstract}
Traditionally, budgeting has been the process through which governments decide how much to spend on what, limiting expenditures to the revenues available and preventing overspending. Over time, budgeting has increasingly been expected to perform different roles and functions, becoming an important political medium, a tool for providing impulses to the economy and the society, a fundamental governance and management device, and a central accountability channel. This multiplicity of functions has translated into a variety of budget formats and bases, and in increasingly complex budgeting processes.
\end{abstract}

This chapter aims to discuss how budgeting has been practiced and studied over the last few decades by looking at the evolution of public budget functions, formats and processes over time, and the related implications and challenges for practice, policy and research. 


\subsection{Introduction}

Public budgets play a central role in public organizations and the economy. A large share of Europe's GDP is managed through public budgets, whereby public expenditure in European countries averagely accounts for around $50 \%$ of GDP (OECD, 2014).

Interestingly, public budgeting appears to be an umbrella-term, used to refer alternatively to a set of documents as well as the decision-making processes and related procedures that surround them. Traditionally, budgeting has been the process through which governments decide how much to spend on what, limiting expenditures to the revenues available and preventing overspending. However, public budgets are also tools for bargaining and allocating power and resources, for planning and controlling, for providing impulses to the economic and social environment, and for ensuring transparency and stakeholder involvement. It is not surprising, then, that public budgets and budgeting are the subject of enduring interest by different disciplines, each focusing on specific facets, functions and features of public budgets, and somewhat suggesting partial views of the related processes, contents and phenomena. Similarly, in practice, budgeting processes involve different actors (politicians, managers, accountants, economists, etc.), each with their own cultures, perceptions, expectations and professional norms.

This chapter is aimed at exploring, reflecting and highlighting public budgets multifaceted nature and the related implications and challenges for practice, policy and research by taking into specific account European developments and trends. In this vein, it first discusses budget functions, focusing on their roles from political, managerial, accountability and economic perspectives. It then looks at public budgets as "documents", exploring how these functions are reflected in different formats, bases and principles. Subsequently, it explores budgeting as processes, pointing to the continuous evolution of approaches to understand and at the same 
time shape budgetary decision-making. Finally, it addresses the possible future challenges for practitioners and researchers interested in public budgeting.

\subsection{The functions of public budgeting}

Public budgets were first created to ensure that no revenues could be raised (and no taxation could be imposed on constituents) without the approval of the constituents' representatives, and that the latter could decide on the use of such public resources. Thus, they were aimed at authorizing the spending of public money, ensuring compliance through budget execution and reporting, ultimately guaranteeing accountability on the decisions as well on the actual use of public resources. As such, public budgets list public sector entities' revenues and expenditures, and generally limit the amount of the latter to the amount of the former, to ensure balance. Also, for each budgetary item (appropriation), they constrain the amount to be spent, ie, during budget execution expenditures will not exceed budgetary appropriations.

Public budgets and budgeting processes in Western Europe and the US developed their modern composition and form between the mid-19th century and the end of WW II (Krause, 2012). Over the years, budgets have increased both their size and scope, and today they can be described as important political media, fundamental governance and management devices, central accountability channels, and important tools for providing impulse to the economy and society.

Budgets play a fundamental political function in that (Rubin, 2010: 1-2) they show what governments and other public sector entities are going to do, with which priorities, and how they plan to fund it. As such, on the one hand they reflect stakeholders' preferences and priorities, and their relative power positions. On the other, budgets reflect the final compromise of long decision making processes, where different interests and priorities are brought to the table, as well as the starting point for future discussions and bargaining (Wildavsky, 1964). The political function is 
probably the one that has traditionally attracted more attention in practice and in scholarly debates and has especially formed the subject of enduring interest by political scientists. The political function of the budget is reflected first and foremost in its centrality in the budgetary cycle as well as the requirement for it to be publicly accessible, which stands in stark contrast with what happens in the private sector, where it is rather financial statements that occupy the center stage, and budgets are not generally disclosed to the public. Second, the political function of the budget significantly affects the form of budgetary processes (eg. procedural aspects, roles and responsibilities of key actors, executive-legislative relationships) and is also reflected in specific features of the format of public budgets, such, as, for example, the specific importance taken on by expenditure breakdown by destination (be it functions, programs, missions, etc.) as opposed to its classification by nature. Indeed, the destination of spending will clearly suggest where the political priorities stand in terms of choosing among competing policy areas.

The political function of budgets is strongly intertwined with their external accountability function. The separation between who pays for taxes and who decides how to spend the money raised through taxations implies that governments should be held accountable for what they spend as well as for the efficiency and effectiveness of programs and services delivered. Accountability is attained on the one hand through the clarity, accessibility, readability and comprehensiveness of budgetary documents, which will include not only the initial budgets, but also the revised ones, and the budgetary reports (showing compliance with budgets). On the other hand, it is to be attained by making budgeting processes transparent and understandable to stakeholders, or by increasingly involving stakeholders. Rubin (2010) observes that governments may be more or less willing to display their own choices on public expenditures and programmes. On the one hand they may be inclined to external communication for leveraging the announcement effect and increase their level of consensus. On the other, they may exhibit a 
certain reluctance to avoid raising expectations of the community about the results to be achieved or to attract the attention of those stakeholders who, being against specific budgetary choices, may contrast them. The external accountability function has traditionally been the subject of attention both from political scientists and law scholars. Increasingly, it has attracted the attention of public management and accounting scholars too, heedful to the accountability implications of budgetary reforms. As such, questions about whether and how cash- or accruals- based formats, or performance based budgeting, or participatory budgeting, can increase the transparency of budgets have become and continue to be the subject of heated debate.

Public budgets also play an important managerial function, in that they facilitate the attainment of mission and strategies set forth by governments and public sector entities, by holding public managers accountable for their results and the use of resources. Indeed, public budgets enable "the programming of approved goals into specific projects and activities, the design of organizational units to carry out approved programs, and the staffing of these units and the procurement of necessary resources" (Schick, 1966, 244). This function has very often been the weakest, as traditionally in the public sector greater importance was attached to the formal respect of spending constraints, which may also have diverted managers' attention from result orientation. However, the managerial function of the budget has entered the spotlight in the wake of managerial movements of reforms (Hood, 1991, 1995), which, in the pursuit of stronger organizational as well as managerial autonomy, accountability, efficiency, effectiveness, value for money, output- orientation, have promoted significant changes in the traditional budget formats and processes. This has translated, as will be shown below, into a trend to adopt accruals-based budgets, or performance-based ones. Along similar lines, managerial reforms have often translated into a stronger distinction between budgets defined at the political and managerial levels. The managerial function of budgets has attracted in particular the attention of public 
management and accounting scholars, who have been particularly interested in understanding how new budget formats and processes have been used to strengthen and clarify managerial responsibilities, to improve service provision, and to introduce result-orientation, being influenced by but ultimately also affecting administrative culture (see also Anessi et al., 2016).

Finally, public budgets perform three main economic functions (Musgrave and Musgrave 1989). The allocative function of public budgeting refers to defining the boundaries of public sector involvement in the economy, i.e. the shares of an economy controlled by governments and by the private sector. The distributive function refers to public budgets defining how the sacrifices and benefits will be distributed among the different categories of actors, giving rise to the neverending and not-easily decipherable debate about the extent to which governments should try to remedy the inequalities between the citizens (see also Musgrave and Musgrave, 1989). Finally, the budget plays a function of stabilization, in that governments use the budget as an instrument of macroeconomic management with the expectation to improve the overall economic performance and to anticipate as well as mitigate economic downturns (e.g., in terms of rate of employments, economic growth, level of inflation). It is worth noticing that the economic functions have become especially central in the middle of the last century, becoming increasingly intertwined with the political one (i.e. budgets as fiscal policies). As such, it is reflected in types of expenditure classification that reflect potential impacts on the economy and on society, such as breakdown by function. Also, it finds expression in fiscal rules and indicators, through which States, as well as international or supra-national institutions try to increase fiscal performance or enhance fiscal discipline. In Europe fiscal rules were introduced at the supra-national level with the 1992 Maastricht Treaty, which established numerical entry criteria to the Economic and Monetary Union. The Maastricht numerical fiscal rules were further strengthened and clarified in the Stability and Growth Pact (1997). Since then, and in particular as a consequence of the fiscal crisis, 
the latter has seen a number of revisions and reforms (e.g. Six-Pack, Two Pack, and Fiscal Compact). Among others, these requirements have resulted in changes of time horizons of budgets, ie the introduction of medium-term planning frameworks with fixed ceilings, aimed at ensuring a stable and sustainable fiscal position in the medium term and beyond. In Europe, they have also contributed to re-shape the roles of budgets as tools for mediating the relationship between the EU and the member states. It is thus not surprising that the economic function has been mostly investigated by economists, and that in the Offices of Budget and Treasury, especially at the central states' level, macro-economic competencies are strongly represented.

A review (Anessi et al., 2016) highlights that the studies of European public budgeting published in Accounting and Public Administration journals between the 80ies and the first decade of the XXI century mostly focused on the managerial function of budgeting, with a slight increase in the attention towards its external accountability role since the '90ies. This appears to reflect the importance taken on by the managerial (NPM) wave of reforms.

The multi-faceted nature of the public budget functions translates into different architectures when it comes to shaping public budgets as documents (including choices as to the classification of items and principles of preparation) and public budgeting as processes (with the related implications in terms of steps, involved actors, relevant responsibilities, and time lines).

\subsection{Public budgets as documents}

The budget is a document or a collection of documents that define the amount of resources available to fund expenditures in a given period of time, usually consisting of one financial year. As documents, public budgets can take significantly different formats and will generally be required to respect a number of budgetary principles. Defining budget formats and principles is not merely a technical issue as it may influence the analysis and discussion underlying budgetary decision, the 
level of accountability and transparency, the way in which responsibilities are allocated among actors within political and administrative sides of governments. In this respect, as Grizzle (1986: 60-61) observes:

'In thinking about how the organization of data might affect budget decision it is useful to conceptualize a two-step process. In the first step, the format in which the proposed budget is cast would influence the content of discussion that budget makers hold during the budget review process. [...] In the second step, the content of budget deliberations, that is, "the nature of budgetary discourse"; would influence the budget decisions that determine how much money is appropriated for what purpose.'

\subsection{Budget formats}

The traditional format of public budget is the line-item one, whereby revenues and expenditures are classified by nature, ie, the former are classified into specific categories that mirror their character such as taxes and fees, and the latter are classified so as to inform on the type of resources which are going to be used and deployed, including personnel, goods and services, interests. Each expenditure category is listed on a separate line of the budget document and budget approval authorizes the actual spending within the budgeted limits. Categories can be defined broadly (for instance contrasting operating and capital expenditures) or can be broken down in many detailed items (further disaggregating both operating and capital expenditures), thus reducing the discretion that is left to the executive branch of government and operating managers. The line-item budget is in tune with the traditional model of public administration because of its potential to closely monitor and limit spending by the execution through the detailed specification of input. However, it does not provide information on what is spent. Several consequences of the missing link between inputs and programs/outputs might be identified. First, 
this kind of structure of the budget tends to downplay competition during budget formulation, discussion and approval because it makes it difficult to understand and compare the programs and actions that the government as a whole and its departments want to realize (Rubin, 2010; Wildavsky, 1978). Second, line-item budget it is not able to promote efficient and effective planning of public spending thus facilitating an incremental approach to definition of expenditures (Shah and Shen, 2007). Third, this type of classification shows a low level of accountability towards external stakeholders that may be expected to be more interested in what activities money is spent on instead of how money is spent. Forth, line-item budget encourages public managers to focus their attention during budget execution more on expenditure ceiling rather than the performance of their activities.

To overcome these shortcomings of the line- item format, several reforms have tried to modify budget formats with the aim of strengthening its planning, accountability and managerial functions. This has led, among others things, to compound information on the nature of expected expenditure with information on their purposes. The concept of "purpose" has been operationalized in terms of administrative units, programs, performance and functions. Each format of the budget by purpose serves different functions and has several pros and cons, discussed below and summed up in Table 7.1.

Expenditure is classified by organizational units when the aim is to emphasize financial control and assign the related responsibilities. This kind of structure of the budget, together with line item appropriations, tends to play down competition during budget formulation, discussion and approval because it makes it difficult to understand and compare the programs and actions that the government as a whole and its departments want to realize (Rubin, 2010; Wildavsky, 1978). This type of classification shows a low-to-medium level of accountability towards external stakeholders that may be expected to be more interested in what activities money is spent on 
instead of organizational distribution of responsibilities. This format might entail problems of comparison of data over time and space as organization structures differ among governments and change over time.

The classification of expenditure appropriations by programs is typical of program budgets. In program budgets appropriations are shown according to activities that the government intends to realize in order to achieve specific objectives (programs), often with a multi-annual time span. This classification is expected to ensure a link between long-term planning and the annual budget. It is also consistent with the role of legislators that are responsible for representing interests and overseeing public expenditures and their underlying strategies and priorities. Moreover, it provides external stakeholders with the information they may seek as it highlights the priorities set by the governments. The change of political programs would also change the structure of the budget, with obvious consequences on the possibility of comparing data over time and space.

Performance budgets reflect government inputs and the related results to be achieved. This format is similar to the program budged, with the exception that in performance budget expenditures per each program are complemented with information related to the expected results. Results can be qualified as outputs (quantity and quality of activities and services provided), efficiency (cost per unit of outputs), outcomes (immediate impacts of outputs) and effectiveness (ratio between outputs and outcomes). Performance budgets mainly pursue managerial and accountability functions, with the outcome budget being even higher on accountability as compared to output budget. Indeed, it has been defined (Martin, 2002, 249) as "external-stakeholder friendly". Performance budgets, similarly to program budgets, make it difficult to compare results within the same government over time and between agencies (see Carlin, 2006). In general, the integration of financial information with non-financial information in budgets has been a widespread trend in Europe since the introduction of NPM reforms, reaching 
its peak in the early 2000s. Interestingly, Northern European States (Norway, Finland, and Sweden) have been among the first-movers in this regard, starting their initiatives in the late 1980s. According to OECD/World Bank survey carried out in 2007/2008 over $75 \%$ of the responding 97 countries across the world (and around 80\% of today's 28 EU member) states incorporate performance information in their budgets or budget processes (see also Willoughby 2014), although a high variety in the maturity of approaches is shown ${ }^{1}$. In this context, studies also show that there is a tendency of countries to introduce initially output budgets and later outcome budgets (for instance Denmark and Netherlands) and to avoid mechanical links between performance results and decision on the allocation of resources, with cut or elimination of resources allocated to those programs that fail to meet performance targets (Curristine, 2005).

Finally, the budget can also be structured to reflect how money is spent on each function that governments are expected to carry out. This classification allows comparisons on expenses on particular functions between countries/governments and over time, mainly providing information for analyzing the economic functions of budgets. The COFOG (Classification of the Functions of Government) is the clearest example of classification by functions. It was developed in 1984 by the United Nation and modified in 1999. The latest version has been adopted by Eurostat to collect data on general government expenditure of EU members. COFOG classifies government expenditure with three levels of detail: divisions; groups; classes. In particular, the ten divisions describe the broad socio-economic functions of government (general public services, defense, public order and safety, economic affairs, environmental protection, housing and community affairs, health, recreation, culture and religion, education, social protection), while groups and classes represent subcategories (e.g. pre-primary education) within the respective division (e.g. education). With the introduction of ESA 2010 the provision of data at the group level has become

\footnotetext{
${ }^{1}$ For more details it is possible to visit the OECD International Database of Budget Practices and Procedures, at www.oecd.org/gov/budget/database
} 
compulsory for all EU member states therefore allowing more detailed comparisons across countries. From a political and managerial point of view its weaknesses however refer to its feeble link to strategic and operational plans and responsibilities as well as the specific aims that an organization wants to achieve with respect to the generic functions is responsible for.

\subsection{The "basis" of budgeting: cash or accruals?}

The appropriations included in the budget can be expressed using different bases of accounting, with the cash and the accrual bases representing the two ends of a spectrum of different alternatives (including modified cash and accruals systems, or commitment based ones) (Jones and Pendlebury, 2010). Traditionally the basis of accounting and budgeting of government has been cash. Cash-based budget shows the estimated collections on the revenues side and expected payments on the expenditure side. During the year, then, revenues are recorded when cash is actually received, whereas expenditures are recorded when they are actually paid. The main advantages of cash-basis accounting and budgeting are its objectiveness and simplicity. However, several disadvantages have been recognized. The main are the following: lack of information on income and costs (that may be relevant even for governments) as well as on assets and liabilities; distortion of the real expenditures and revenues of a fiscal year as consequence of the fact that values that do not result in cash transactions are not recorded; manipulations in budget execution as collections and payments can be speeded up or slowed down. In the wake of NPM reforms attempts have been made to replace the traditional cash basis with the accrual basis both for accounting and financial reporting and for budgeting. Under accrual accounting, revenues are recorded when earned and expenditures when a liability is incurred regardless of when cash flows take place. This different basis of accounting and budgeting is claimed to have a number of advantages In this respect, several authors, specifically focusing on the UK's "Resource accounting 
and budgeting" (RAB) initiative, have pointed out this benefits of accrual-based budgeting: better information and incentives to manage assets; better incentives in planning investments and, more generally, a new impetus to bring under control the sustainability of public finances by highlighting the long-term consequences of current decisions. However, the introduction of accrual-based budgets raises some critical issues as well, such as the accounting treatment of specific operations and items, including nonreciprocal revenues, pension liabilities and entitlements (Gillibrand and Hilton 1998; Likierman, 1998; Likierman 2003; Hepworth 2003; Adam and Behn 2006), the implications on the amount of cash to be appropriated of the inclusion of non-cash items under an accrual framework (is cash appropriated for the full accrual amounts, including non-cash items such as depreciation?) (Blöndal 2004), the rise of creative accounting (Perrin 1998), the need to enable non-accountants to understand and use the new information (Likierman, 2000). However, in practice, in the second decade of the 21st century a full move to the accruals basis of budgeting has not yet (?) taken place. For example, the majority of European countries have not opted for accruals appropriations, even when most of them have implemented accrual accounting and/or reporting (see chapter 8 in this book), substituting or complementing cash-based accounting and/or reporting (Table 7.1). This is also the solution implemented by the European Union that elaborates its budget on cash accounting principles, whereas the accounting system recognizes revenues and expenditures according to both the cash basis and the accrual basis and financial report includes both cash- and accrual-based statements. These hybrid solutions in which both cash and accrual bases are used in various combinations along all the budgetary cycle or only in some stages mirror a compromise that appears far from being beneficial, given that might produces confusion in politician and managers providing them with conflict and not-comparable information (see also Guthrie, 1998). 
FINANCIAL REPORTING

\begin{tabular}{|c|c|c|}
\hline & \\
\hline & (Modified) Cash & (Modified) Accrual \\
\hline \multirow[t]{11}{*}{ (Modified) Cash } & (Albania) § & Belgium \\
\hline & (Bosnia) § & Czech Republic \\
\hline & Bulgaria & France \\
\hline & Croatia & Greece \\
\hline & Cyprus & Hungary \\
\hline & Germany & Latvia \\
\hline & Ireland & Lithuania \\
\hline & Italy & (Montenegro) § \\
\hline & Luxembourg & Poland \\
\hline & (Macedonia) § & Portugal \\
\hline & Malta & Romania \\
\hline \multirow[t]{5}{*}{ BUDGETING } & Netherlands & Slovakia \\
\hline & (Norway)§ & Spain \\
\hline & (Serbia)§ & \\
\hline & Slovenia & \\
\hline & (Ukraine)§ & \\
\hline
\end{tabular}

(Modified) Accrual

Austria

Denmark

Finland

Estonia

(Iceland)§ 
Source: Brusca et. al. (2015), Christiaens et. al. (2014), Ernst and Young (2012), Moretti (2016) and authors' Elaboration (Country)§ = Non EU member

\subsection{Budget principles}

Irrespective of how appropriations are presented, budgets are generally required to comply with a number of principles, including: transparency, whereby information on the budget and its implementation must be publicly available; unit of account, as the budget must be drawn up and implemented in one currency; annuality, as the budget generally refers to one financial year; universality, as all revenues and expenditures are included in the budget; unity, whereby all revenues contribute to covering all expenditures. Another fundamental principle governing budgeting is the requirement that budget should balance revenues to expenditure, or that budgeted deficits should not exceed a given threshold.

In this respect, some empirical evidence does exist that budgets are often optimistic or pessimistic in that expected budgeted revenues and expenditures are often over- or underestimated, giving rise to bias in budgeting and the subsequent emergence of surpluses or deficits. A certain degree of inaccuracy in forecasting is considered unavoidable, due to the presence of uncertainty about the future (Rubin 1987). Inaccuracies, however, may be intentional (Larkey and Smith, 1989), with budgets reporting something different from what is suggested by the models and data at their disposal. Several explanations for intentional budget bias are identified. The benefits of intentional misrepresentation at the budgetary stage, however, can be short-lived. Indeed, during the fiscal year, actual revenues and expenditure will emerge as different from the 
budgeted ones, forcing immediate actions to be taken, for example in terms of downward revision of spending, or the necessity to cover a deficit in the following years. A recent study of Italian municipalities by Anessi and Sicilia (2015) suggests that overestimations of current revenues are more frequent than underestimations, during both budget formulation and budget execution, and that they are associated with political orientation and fiscal stress

\subsection{Budgeting as process}

When looking at public budgeting as a collection of processes, it is necessary to recognize that the budgetary cycle is not restricted to the budget formulation, ie the process through which decisions are taken on the expenditures, the revenues and the budget is approved, but also includes budget execution and reporting. This integrated view is crucial for ensuring political and administrative accountability along the process. One important feature in public budgeting is therefore the obligatory and publicly available comparison of budgeted and actual amounts (e.g. revenues, expenditures, programs, performance indicators), which ensures budget execution control. As the political-administrative process is tailored around budget preparation, budget execution and reporting appear to have attracted less attention in research and practice. A few studies, however, have shown the relevance of considering these elements. During budget execution, public budgets can be significantly modified, and thus initial budgeting and budget execution must be viewed as the components of a yearlong process. More specifically, as shown by Anessi et al (2012) in a study of Italian municipalities, budget formulation and re-budgeting during the year tend to be complementary, ie, the more a policy has been incorporated into the initial budget, the less it needs to be pursued through re-budgeting.

Budgetary processes are generally regulated by laws or rules referring to how the different phases develop, who the actors involved are, with which powers, as well as the degree of publicity 
of such processes. Beyond these legal perspectives, in particular the stage of budget preparation comprises complex decision making processes, where interests and priorities of multiple actors are brought to the table and where "who gets what, how and why" is not only dependent on rational decisions, technical rules and procedures, but also on past decisions, relative power relationships, alliances, bargains, the politics of the process and changes in the environment (Wildavsky, 1964: 322; Wildavsky, 1992). Along these lines, the history of budgeting research and practice displays a succession of phases as well as a continuous tension between opposites such as incremental and comprehensive (rational) processes, growth and decline, centralization and decentralization, as well as macro and micro-oriented processes (Caiden, 2010).

The incremental dimension of budgeting processes has been emphasized by several scholars (e.g. Wildavsky 1964, Caiden, 2010), becoming a mainstream explanation for budgeting processes in the US and also in Western Europe (van Nispen, 2011) after WWII. In terms of budgetary outputs, incrementalism broadly reflects decisions that use last year's budgets to develop this year's budgets by making marginal adjustments resulting in stable patterns over time. In terms of budgetary processes, incrementalism has been seen as a way to simplify budget decisions and to reduce conflict over decisions related to the allocation of money, making budgeting more comprehensible and predictable, where the involved actors largely know the results in advance (Andersen and Mortensen, 2009). Although incrementalism has been considered as one of the most powerful descriptions of real-life budgeting processes, it has been also significantly criticized as it may result in conservatism, short-termism and the support of existing coalitions and policies (Rainey 2009, Rubin 1989). Moreover, its explanatory power is considered to be limited to specific environmental conditions (i.e. a stable and growing economy), to a specific type of budget (i.e. line-item budgeting) and to a specific type of process (i.e. bottom-up process) (Rubin 1989), where the budgeting power is concentrated in the knowledge of the executive branch and agency heads 
drive budget decisions (micro-budgeting) while politicians only discuss the increments from an already existing budgeting base. As a result, budgets should remain stable. This pattern is often found; for example, according to Barracclough and Dorotinsky (2008), in most OECD countries, the legislature approves the executive budget proposal without major changes, ie, less than 3 percent. However, an increasing number of empirical studies revealed that budgets are occasionally punctuated by large shifts in budget positions (Jones et. al. 2009), thereby suggesting that punctuated equilibrium theory may prove a useful alternative theory in explaining budgeting outputs over time. According to proponents of this theory, stability is interrupted by significant variations caused by important changes in society, politics, institutions and the economy (Baumgartner et al, 1998). While incremental approaches to budgeting therefore have to be acknowledged as one trait of budgeting, they seem to be rather suited to continue a stable past into a predictable future, while falling short of shaping the future directions of government or society (Schick, 2004) or dealing effectively with environmental challenges.

Historically, there have often been efforts to make budgeting processes more rational and to improve the quality of budget decisions by altering budget formats, providing richer information on financial and non-financial performance of public programs and services, changing decision making processes and responsibilities as well as timeframes. The critique of incrementalism, traditional budget formats and the budget power of the executive have also given rise to reform movements such as those taking place in the '60ies and '70ies, that aimed at increasing the comprehensiveness and rationality of budgeting processes. Planning and programming approaches (e.g. Planning, Programming, Budgeting Systems, Zero-based budgeting), inspired by trust in centralized and top-down processes and a strong focus on the economic function of budgeting, were adopted in the US and several European countries (e.g. Italy, France, Belgium, Sweden, Germany). Due to technological, organizational and political 
reasons, however, these approaches were never fully implemented or were abandoned, particularly in the face of the late "70ies crisis and related austerity. Indeed, the 1970ies and early 1980ies witnessed the emergence of "decrementalism", ie, the translation of incrementalism under constrained resources, expressed as 'equity cuts' and sharing the pain among units. However, this translation goes beyond merely mirroring incrementalism since it happens in less stable environments and generates more conflict (Schick, 1983). Acknowledging the latter resulted in a need to not only discuss the margins of public budgets but to adopt - again - more "comprehensive and rational approaches" (taking a multiyear time frame, implementing a comprehensive re-examination of mission and structure and involving a significant reallocation of resources), that have been described in the rich cutback management literature (Levine, 1978, 1979, 1985; Hood and Wright 1980, Schick, 1980). The latter disappeared (for a long time), but probably paved the way for the latest rationalization phase, under NPM. More specifically, budgeting under NPM focuses on decentralized and managerial decision-making and relies on a strong confidence on the effectiveness of technical-rational approaches. In particular, the use of performance information throughout the budgeting processes and in budget documents is considered as a crucial element in achieving better decisions and in enhancing the efficiency, effectiveness and accountability of public organizations. This emphasis has partially been displaced in the face of the global financial crisis, whereby, especially in Europe, new attention has been given to the definition and enforcement of fiscal rules, supra-national control over budgeting, while new attention to cutback management and austerity (re-)emerged in practice and in the literature (for example, Peters, 2011; Raudla et al., 2013; Bracci et al., 2015; Kickert and RandmaLiiv, 2015). Thus, it can be concluded that approaches to budgeting will tend to sediment over time, giving rise to unique combinations of rules and routines that continuously evolve in a path dependent way. 
However, it may be pointed out that NPM appears to have played a major role in affecting both the features of budgeting and related research between the end of the XX century and the beginning of the XXI. Indeed, a review of public sector budgeting in Accounting and Public Management journals (Anessi et al. 2016) shows that the majority of papers on public budgeting (61 out of 83) refer to NPM as a context or even a conceptual lens to read budgetary reforms. Interestingly, strong reliance on NPM literature may have temporarily displaced attention from the development of theories of public budgeting in Europe, but appears to have been conducive to the accumulation of rich descriptive contextual evidence on public sector reforms in different countries and the related changes in budgeting regimes. This, in turn, may provide the basis for the development of more advanced theories of public budgeting, which explain not only variation across space, but also over time. Indeed, the review shows that over time the papers have become theoretically more sophisticated, probably reflecting an evolution whereby the initial exploration of practices and reforms has paved the way for conceptually stronger analyses.

However, there is still a lack of research with regard to the impact of changes in budget formats on budgeting processes. In Europe, only a few scholars have analyzed the use of performance information in budgeting processes and their impact on the roles and responsibilities of politicians and managers (e.g. Raudla 2011). These studies also revealed that performance information in budgeting processes is mainly used for presentational/informational purposes without changing the accountability relationship between the legislative and executive branch. Although the results are not surprising for various and well documented reasons (e.g. Schick, 2007, Wildavsky, 1978), they point to a general weakness of reforms which are mainly based on technical-rational assumptions and ignore the political and cultural surrounding context. Technical tools can, in principle, support better decision making, however they are also shaped by, and in turn also influence organizational, psychological, economic, social and political contexts (Liguori 
and Steccolini, 2014). Table 7.2 sums up the evolutions in the main functions and features of public budgeting over time.

Table 7.2 Evolutions in public budgeting

\begin{tabular}{|c|c|c|c|}
\hline & $\begin{array}{l}\text { DOMINANT } \\
\text { FUNCTIONS }\end{array}$ & FORMATS & PROCESSES \\
\hline Traditional PA before & Political and (internal) & Detailed Line-Item & Incrementalism \\
\hline \multirow[t]{3}{*}{ II WW } & accountability & Budgets & \\
\hline & Focus: budgetary & Cash-based budgets & \\
\hline & compliance & & \\
\hline Post-war expansion & Political and (internal) & Line item (broader & Incrementalism \\
\hline \multirow[t]{4}{*}{$1950-1970$} & accountability function & categories) & Programme budgeting as \\
\hline & Economic functions & Programme Budgets & antidote to incrementalism \\
\hline & Focus: impact on the & Budgets by functions & \\
\hline & Economy & Cash based budgets & \\
\hline Austerity (I) and & (Internal) accountablity & Line-item or programme & Decrementalism \\
\hline cutback management & function & budget & Top down budgeting \\
\hline \multirow[t]{3}{*}{$1970-1980$} & Economic functions & Cash based budgets & Cutback management \\
\hline & Focus: expenditure & & Spending reviews \\
\hline & control & & \\
\hline NPM & Managerial Function & Budgets by & Strategic and rational \\
\hline \multirow[t]{3}{*}{ 1980s - } & Accountability Function & organizational units & processes \\
\hline & Focus: performance; & Performance Budgets & Linking resources with results \\
\hline & value for money & Accruals based budgets & \\
\hline Austerity (II) & (External) accountability & Budgets by & Fiscal Governance \\
\hline
\end{tabular}


function

Economic functions

Focus: macro-economic

and fiscal policies; debt

and spending reduction
functions/COFOG

(Supranational) Macro-

Performance budgets Budgeting

Spending reviews

Fiscal rules 


\subsection{Future challenges for budgeting scholars, practitioners and policy makers}

The above reflections show that public budgeting is multifaceted, in that it can be observed from different angles and points of views, and it is also a complex phenomenon, which shows significant variation across space and over time. In spite of this, a review of European literature points out that public budgeting has attracted scant consideration in public management and accounting research in Europe over the last thirty years (Anessi et al., 2016) with most contributions rather rooted in the grey literature, i.e being published as policy briefs or reports, rather than as articles in scientific journals. Also, it highlights that, in spite of the changes advocated for by managerial reform movements, changes in public budgeting, including shifts to performance-based and accruals-based budgeting, are still under way, or their expected benefits are yet to be fully reaped. The post-crisis and austerity context are further increasing the complexity of the budgeting context and processes, and, thus, it can be expected that in the years to come budgeters as well as public budgeting scholars will face new challenges. This section provides an overview of these likely challenges.

\subsubsection{Budget formats, processes and the changing environment}

In 1978 Wildavsky $(1978,508)$ suggested that the traditional line item budget had lasted long because it had "the virtues of its defects", ie, it is easier, simpler, more flexible and more controllable than alternative models, which are usually designed to address a specific aim, on which they score particularly well, but which will then tend to be unsatisfactory to attain other aims.

Is this still the case in the wake of the transformations occurring at the outset of the XXIst century? Managerial reforms have suggested the move to an increased reliance on accruals- and performance- based budgets. However, the integration of financial and non-financial aspects of 
performance, and of budgeting and performance management still remains a puzzle for many reformers and budgeters. Indeed, an increasing body of literature shows that accruals data are not necessarily preferred by either managers or politicians (for a review of relevant literature, see Liguori et al., 2012, 2014), as non-financial performance measures and cash-based data may appeal more to their users' needs. In this respect, some authors suggest that the accruals basis of accounting may be useful for reporting and as an analytical tool, but still may not be needed as a basis for budgeting (Caiden, 2010, in discussing Schick's work). Thus, while the literature on the adoption of accruals accounting has become increasingly wide, much less attention has been devoted so far, both in the literature and in practice, to how accruals-based budgeting should work and actually works, or at its impacts for political as well as managerial decision making (for a few notable exceptions, see Ezzamel et al., 2007; Hyndman and Connolly, 2011).

Similarly, the integration of financial and non-financial performance goals still remain challenging for budgeters, both in the formulation and execution stages of budgeting. The actual use of performance data to feed this process still remains a puzzle for scholars and policy makers alike. This raises not only the need to further investigate (performance) information processing capacities of different actor groups but also to consider different types of uses of performance information. More generally, as in the past political and managerial processes have often been looked at separately, even by different disciplines, there is a need to devote increased attention to how such processes intertwines and influence each other also considering the multiple rationalities and logics, i.e. managerial/administrative and political, that are at play.

The austerity phase that started after the 2008 global crisis appears to have sharpened these difficulties. In general, the banking, economic and - in many EU countries - fiscal crises and the rise of the ideology of austerity observable during the period 2009-15 may have caused a recentralization of processes, and the induced increased uncertainty and turbulence may have 
resulted in fragmented decision making and the need of continuous changes and adjustments to budgets, in their formulation as well as in their execution. This signals the need for practitioners and scholars to devote more attention to how fiscal rules and constraints, and a search for stability in public finances (macro-budgeting), can go hand in hand, or even require, increased flexibility in budget execution (micro-budgeting).

More specifically, as Bracci et al (2015) point out, the NPM official rhetoric was about promoting the principles of the market, encouraging competition, results-oriented behavior, the quantification of performance and an emphasis on value-for-money. Austerity (particularly in the European Union) appears to have brought about an evident shift in accountability relationships and meanings. Under austerity, the attention has shifted to macro-data such as debt/GDP and deficit/GDP ratios, debt ceilings, balanced budgets (ie, macro-budgeting). Euro-zone countries have introduced balanced-budget amendments in their Constitutions (or adopted similar "domestic implementation laws") and strengthened the chain of budgetary accountability across tiers of government. There is now a greater emphasis on the state of public finances at the country-level, rather than at an organizational level, while 'non-financial' aspects have been marginalized: On the one hand, austerity appears to have encouraged prioritization of services and policies, thus requiring the simultaneous consideration of the financial and non-financial aspects of public services. At the same time, it may have emphasized financial constraints and/or goals at the expense of the non-financial ones, thus strengthening the traditional focus on money and cash in the budget process. Indeed, austerity appears, in many countries (see also Bracci et al., 2015) to have meant a stronger focus on centralized financial and fiscal decision making, reversing the effects or intentions of the managerial move of former reforms, which were rather aimed at strengthening decentralized decision making, and refocusing the attention also on the effectiveness and quality of services. 
These developments suggest that we may soon face the paradox that Wildavsky highlighted in the 1980ies, whereby budget reforms that were introduced under the managerial movement with the aim of strengthening managerial accountability and result orientation may find application in a significantly changed context and thus be potentially at odds with new budgeters' needs. It will thus be interesting to explore whether the managerial reforms of the 1980ies, 1990ies and partly the 2000ies have provided better performing budget documents to public sector organizations or, rather, they have left them worse equipped to face difficult times.

\subsubsection{Co-production, citizens' participation and external accountability}

Public sector managerial reform initiatives have increasingly emphasized the importance of accountability towards external stakeholders (Steccolini, 2004) as well as of their involvement and participation in decision making processes and service delivery (Bovaird, 2007). From a budgeting point of view, external accountability and participation require not only clear and comprehensive communication, but also forms of citizen and stakeholder involvement and participation, despite the obvious challenges posed by the virtual absence of interest by many stakeholders, and especially external ones (see, for example, Jones and Pendlebury, 2010; Mack and Ryan, 2007; Steccolini, 2004;). This stimulates an interest in looking at how budgeting processes can support co-production logics and processes, for example through forms of participatory budgeting. Participatory budgeting is different from traditional budgeting processes (Wildavsky, 1964; Rubin, 2010), where decisions are made by elected or other government officials, that is, where citizens' choices are mediated through their representatives. Participatory budgeting requires citizens to be directly involved in budgeting processes and responsible for decisions about budget allocations (Allegretti and Herzberg, 2004; Pinnington et al., 2009), and to ensure conditions of interaction, 
inclusiveness, responsiveness and representation in the whole process (Barbera et al., forthcoming).

\subsubsection{Budgeting, public governance and inter-organizational arrangements}

As public service delivery increasingly requires the involvement of multiple actors, including other governments or public sector entities, as well as private and nonprofit organizations, this has important implications for budgeting. On the one hand, this has produced new, often hybrid organizational forms; on the other hand, it entails the development of practices and processes that ensure the proper running of these hybrid forms and, thus, the effective provision of services. While hybrid organizational forms have attracted sufficient scholarly attention, the need exists to further investigate the hybrid practices and processes (Miller et al., 2008) that facilitate information flows and coordination across organizational boundaries. Budgeting plays a major role in the allocation of resources and responsibilities, as well as in the discharge of accountability in inter-organizational relationships. As such, the increasing importance of the relationships involving public, private, and nonprofit organizations requires a deeper analysis of the development, use, and impacts of such new tools as pooled or consolidated budgets, as well as a better understanding of the factors affecting the choice and design of the related practices and processes.

At the same time, the increasing attention that is being devoted to the European fiscal governance, the willingness to put public finances "under (central) control" point to the budgets as central in mediating the relationships between member states and inter- or supra-national institutions, between national, intermediate, and local governments, and among governments of the same level. This has important implications. On the one hand, while international standards for financial reporting have existed for long in the private sector, and have increasingly been 
developed, though do not necessarily applied, for the public sector (not without criticism, for example Grossi and Steccolini, 2015), the same has not happened with budgeting standards. Only in the new century the debate about harmonization of public sector accounting standards (see chapter by Cohen at al., this volume) has been extended to budgets and budgeting. However, as much as there is controversy when public sector accounting standards are concerned, this may extend to budgeting ones. On the other hand, and more generally, this suggests that budgeting cannot be seen merely as a series of documents, and processes, but, especially in the European arena, must be increasingly seen as the complex, multifaceted and inherently technical language central in mediating the relationships across actors, institutions, generations by virtue of its political, accountability, managerial and economic functions.

\subsection{Conclusion}

Traditionally, budgeting has been the process through which governments decide how much to spend on what, limiting expenditures to the revenues available and preventing overspending. Over time, budgeting has increasingly been expected to perform different roles and functions, becoming an important political medium, a tool for providing impulses to the economy and the society, a fundamental governance and management device, and a central accountability channel. This multiplicity of functions has translated into a variety of budget formats and bases, and in increasingly complex budgeting processes. This chapter has intended to explore how this multiplicity of functions is reflected in different formats, bases and principles of budgetary documents and in increasingly complex budgetary decision-making processes. Moreover, possible future challenges for practice, policy and research by taking into specific account European context, developments and trends have been highlighted and discussed. 


\section{References}

B. Adam and C. Behm (2006) 'The use of budget reforms to modernize governance in German local government', Public Money and Management, 26, 217-220.

G. Allegretti, and C. Herzberg (2004). Participatory budgets in Europe, Between efficiency and growing local democracy. Transnational Institute and the Centre for Democratic Policy-Making.

S. C. Andersen and P.B. Mortensen (2009) 'Policy Stability and Organizational Performance: Is There a Relationship?', Journal of Public Administration Research and Theory, 20, 1-22.

E. Anessi Pessina, C. Barbera, M. Sicilia, I. Steccolini (2016) ‘Public sector budgeting: A European review of accounting and public-management journals', Accounting, Auditing and Accountability Journal, 29, 491-519.

E. Anessi Pessina, M. Sicilia (2015) 'Biased budgeting in the public sector: Evidence from Italian Local Governments', Local Government Studies, 41, 819-840.

E. Anessi Pessina, M. Sicilia, I. Steccolini (2012) ‘Budgeting and Rebudgeting in Local Governments: Siamese Twins?', Public Administration Review, 72, 875-884.

E. Anessi Pessina (2007) L'evoluzione dei sistemi contabili pubblici: Aspetti critici nella prospettiva aziendale (Milano: EGEA).

E. Anessi Pessina, and I. Steccolini (2007) ‘Effects of budgetary and accruals accounting coexistence: Evidence from Italian local governments', Financial Accountability and Management, $23,113-131$. 
C. Barbera, M. Sicilia, I. Steccolini. (forthcoming). 'The participatory budgeting as a form of coproduction' in E. Bracci, M. Fugini, M. Sicilia (ed.), Co-production for Public Services (Milan: Springer).

F.R. Baumgartner, B. D. Jones and J. L. True (1998) ‘Policy Punctuations: U.S. Budget Authority 1947-1995', Journal of Politics, 60, 1-33.

J.R. Blöndal (2004) 'Issues in accrual budgeting', OECD Journal of Budgeting, 4, 103-119.

K. Barracclough and B. Dorotinsky (2008) 'The role of the legislature in the Budget drafting process: a comparative review' in Stapenhurst et. al. Legislative Oversight and Budgeting - a world perspective (Washington D.C.: The World Bank), 99-110.

T. Bovaird (2007) 'Beyond Engagement and Participation: User and Community Coproduction of Public Services', Public Administration Review, 67, 846-860.

E. Bracci, C. Humphrey, J. Moll, I. Steccolini (2015) ‘Public sector accounting, accountability and austerity: more than balancing the books?', Accounting, Auditing \& Accountability Journal, 28, 878 $-908$.

I. Brusca, E. Caperchione, S. Cohen, F. Manes Rosi (2015), 'Public Sector Accounting and Auditing in Europe: The Challenge of Harmonization (XXX, Palgrave Macmillan)

N. Caiden (2010) 'Challenges confronting contemporary public budgeting: retrospectives/prospectives from Allen Schick', Public Administration Review, 70, 203-210.

T.M. Carlin (2006) 'Victoria's accrual output based budgeting system: Delivering as promised some empirical evidence', Financial Accountability and Management, 22, 1-19. 
J. Christiaens, C. Vanhee, F. Manes-Rossi, N. Aversano, P. Cauwenberge (2015) 'The effect of IPSAS on reforming governmental financial reporting: an international comparison', International Review of Administrative Sciences, 1, 158-177.

T. Curristine (2005) 'Performance Information in the Budget Process: Results of the OECD 2005 Questionnaire', OECD Journal on Budgeting, 5, 87-131.

Ernst and Young, 2012, 'Overview and Comparison of Public Accounting and Auditing Practices in the 27 EU Member states', Prepared for Eurostat, Final Report, December 2012

M. Ezzamel, N. Hyndman, A. Johnsen, I. Lapsley and J. Pallot (2007) ‘Experiencing institutionalization: the development of new budgets in the UK devolved bodies', Accounting, Auditing and Accountability Journal, 20, 11-40.

A. Gillibrand and B. Hilton (1998) 'Resource accounting and budgeting: principles, concepts and practice: The MoD case', Public Money and Management, 18, 21-28.

G.A. Grizzle (1986) ‘Does budget format really govern the actions of budget makers?’ Public Budgeting \& Finance, 6, 60-70.

G. Grossi and I. Steccolini (2014) 'Guest Editorial: Accounting for public governance', Qualitative Research in Accounting \& Management, 11, 86-91.

G. Grossi and I. Steccolini I (2015) ‘Pursuing Private or Public Accountability in the Public Sector? Applying IPSASs to Define the Reporting Entity in Municipal Consolidation', International Journal of Public Administration, 38, 325-334.

J. Guthrie (1998) 'Application of accrual accounting in the Australian public sector: rhetoric or reality?' Financial Accountability and Management, 14, 3-19. 
N. Hepworth (2003) 'Preconditions for successful implementation of accrual accounting in central government', Public Money and Management, 23, 37-44.

C. Hood (1991) 'A public management for all seasons?', Public Administration, 69, 3-19.

C. Hood and M. Wright (1981) 'From Decrementalism to Quantum Cuts?' in C. Hood and M. Wright (ed.) Big Governments in Hard Times, (Oxford: Martin Robertson), 199-227.

N. Hyndman and C. Connolly (2011) 'Accruals accounting in the public sector: a road not always taken. Management Accounting Research', 22, 36-45.

R. Jones and M. Pendlebury (2010) Public sector accounting, 6th edn (London: Pitman).

B. Jones et. al. (2009) 'A General empirical Law of Public Budgets: A comparative analysis', American Journal of Political Science, 53, 855-873.

W.J.M. Kickert and T. Randma-Liiv (2015) Europe Managing the Crisis: The Politics of Fiscal Consolidation (London and New York: Routledge/Taylor and Francis).

P. Krause (2012) 'Executive Politcis and the Governance of Public Finance' in M. Lodge \& K. Wegrich (ed.) Executive Politics in a time of crisis (Palgrave Macmillan), 136-156.

P.D. Larkey and R.A. Smith (1989) 'Bias in the formulation of local government budget problems', Policy Sciences, 22, 123-166.

C.H. Levine (1978) 'Organizational Decline and Cutback Management', Public Administration Review, 38, 316-325.

C.h. Levine (1979) 'More on Cutback Management: Hard Questions for Hard Times', Public Administration Review, 39, 179-183. 
C.H. Levine (1985) 'Police Management in the 1980s: From Decrementalism to Strategic Thinking', Public Administration Review, 45, 691-700.

C.H. Levine and P.L. Posner (1981) 'Centralizing Effects of Austerity on the Intergovernmental System', Political Science Quarterly, 96, 67-85.

M. Liguori and I. Steccolini (2014) 'Accounting, innovation and public-sector change. Translating reforms into change?', Critical Perspectives on Accounting, 25, 319-323.

M. Liguori, M. Sicilia and I. Steccolini (2012) 'Some like it non-financial... politicians' and managers' views on the importance of performance information', Public Management Review, 14, 903-922.

A. Likierman (1998) 'Resource accounting and budgeting. Where are we now?' Public Money and Management, 18, 17-20.

A. Likierman (2000) 'Changes to managerial decision-taking in U.K. central government', Management Accounting Research, 11, 253-261.

A. Likierman (2003) 'Planning and controlling UK public expenditure on a resource basis', Public Money and Management, 23, 45-50.

J. Mack and C. Ryan (2006) 'Reflections on the Theoretical Underpinnings of the General-purpose Financial Reports of Australian Government Departments', Accounting, Auditing \& Accountability Journal, 19, 592-612.

L.L. Martin (2002) 'Budgeting for outcomes' in A. Khan and B. W. Hildreth (ed.) Budget theory in the public sector (London: Quorum Books), 246-260.

P. Miller, L. Kurunmäki and T. O’Leary ‘Accounting, Hybrids and Management of Risk', Accounting Organizations and Society, 33, 942-967. 
D. Moretti (2016) 'Accrual practices and reform experiences in OECD countries Results of the 2016 OECD Accruals Survey', in OECD Journal on Budgeting, 16, 9-28

R.A. Musgrave and P.B. Musgrave (1989) Public finance in theory and practice, 5 th edn (New York: McGraw-Hill).

OECD (2014), National Accounts at a Glance 2014 (Paris: OECD Publishing).

B.G. Peters (2011) 'Governance Responses to the Fiscal Crisis-Comparative Perspectives', Public Money \& Management, 31, 75-80.

E. Pinnington, J. Lerner and D. Schugurensky (2009) 'Participatory budgeting in North America: the case of Guelph, Canada', Journal of Public Budgeting, Accounting and Financial Management, 21, 454-463.

H.G. Rainey Understanding and managing public organizations, $4^{\text {th }}$ edn (San Francisco: JosseyBass)

R. Raudla, R. Savi and T. Randma-Liiv (2013) Literature Review on Cutback Management (Cocops Workpackage 7).

S.I. Rubin (1989) 'Aaron Wildavsky and the demise of incrementalism', Public Administration Review, 40, 78-81.

S.I. Rubin (2010) The politics of public budgeting, 6th edn (New York: Seven Bridges Press).

S.I. Rubin (1987) 'Estimated and actual urban revenues: Exploring the gap', Public Budgeting \& Finance, 7, 83-94.

A. Schick (1966) 'The road to PPB: The stages of budget reform', Public Administration Review, 26, 243-258. 
A. Schick (1980) 'Budgetary Adaptations to Resource Scarcity' in C.H. Levine and I. Rubin (ed.) Fiscal Stress and Public Policy (London: Sage Publications), 113-134.

A. Schick (1983) 'Incrememtal Budgeting in a Decremental Age', Policy Sciences, 16, 1-25.

A. Schick (2007) 'Performance Budgeting and Accrual Budgeting: Decision Rules or Analytic Tools?' OECD Journal on Budgeting, 7, 109-140.

A. Schick (2004) 'Twenty-fice Years of budgeting Reform', OECD Journal on Budgeting, 4, 82-102.

A. Shah and C. Shen (2007) 'A Primer on Performance Budgeting' in A. Shah (ed.) Budgeting and Budgetary Institutions (The World Bank) 137-178.

I. Steccolini (2004) 'Is the Annual Report an Accountability Medium? An Empirical Investigation into Italian Local Governments', Financial Accountability \& Management, 20, 327-350.

F.K.M Van Nispen (2011). Budget Watcher's Blues: Introduction to the Section on Budgeting and Finance, in B.G. Peters \& J. Pierre (Eds.), Handbook of Public Administration. London/Thousand Oaks/New Delhi: Sage Publications, 2011, 463-464

K. Willoughby (2014) Public Budgets in Context: Structure, Law, Reform and Results (San Francisco, Jossey-Bass).

A.B. Wildavsky (1964). The politics of the budgetary process (Boston: Little, Brown).

A.B. Wildavsky (1978) 'A budget for all seasons? Why the traditional budget lasts', Public Administration Review, 38, 501-509.

A.B. Wildavsky (1986) Budgeting: A comparative theory of budgetary processes (New Brunswick, NJ: Transaction Books). 
A.B. Wildavsky (1992) The politics of the budgetary process, 2nd edition (New York: Harper Collins). 